\title{
CONTRIBUIÇÕES DA MEDITAÇÃO EM SITUAÇÃO DE DISTANCIAMENTO SOCIAL: PANDEMIA SARS-COV-2
}

\section{ARTIGO DE REVISÃO}

COSSIA, Tatiana ${ }^{1}$, SEPULVEDA, Nicolly Oliveira ${ }^{2}$, MORAES, Lucas Ferreira de ${ }^{3}$

COSSIA, Tatiana. SEPULVEDA, Nicolly Oliveira. MORAES, Lucas Ferreira de. Contribuições da meditação em situação de distanciamento social: pandemia SARS-COV-2. Revista Científica Multidisciplinar Núcleo Do Conhecimento. Ano 06, Ed. 06, Vol. 09, pp. 110-124. Junho De 2021. ISSN: 2448-0959, Link de acesso: https://www.nucleodoconhecimento.com.br/saude/meditacao-em-situacao, DOI: 10.32749/nucleodoconhecimento.com.br/saude/meditacao-em-situacao

\section{RESUMO}

A pandemia ocasionada pelo SARS-COV-2 atravessou todos os contextos sociais, não desviando de nenhuma extensão da vida coletiva ou individual e repercutindo no âmbito da saúde mental. Como medida de controle da propagação do vírus, diversos países adotaram o distanciamento social, acarretando consequências psicológicas decorrentes da privação social e confinamento. Esse artigo teve como objetivo relacionar os benefícios das práticas da meditação na evidência da empatia como subsídio na promoção de saúde mental durante a quarentena. Foi realizada uma revisão integrativa da literatura, nas bases de dados SciELO; BVS; PubMed e IBICT, de estudos publicados entre 2003 e 2020, disponíveis na íntegra nas línguas

\footnotetext{
${ }^{1}$ Mestre em Educação Profissional pela Universidade Municipal de São Caetano do Sul. Docente na Universidade Anhembi Morumbi, São Paulo, SP, BR.

2 Enfermeira pela Universidade Anhembi Morumbi, São Paulo, SP, BR.

${ }^{3}$ Graduando em Enfermagem pela Universidade Anhembi Morumbi, São Paulo, SP, BR.
}

RC: 88690

Disponível em: https://www.nucleodoconhecimento.com.br/saude/meditacao-em-situacao 
portuguesa e inglesa. Portanto, nesta pesquisa foi identificada que a utilização da meditação, principalmente no período de pandemia, exerce um grande papel na redução dos efeitos psicológicos negativos e promotora de empatia, principalmente por ser uma prática que não requere grandes recursos financeiros.

Palavras-chave: Ansiedade, Saúde Mental, Infecções por Coronavírus, Meditação, Terapias Complementares.

\section{INTRODUÇÃO}

Em dezembro de 2019, identificou-se um novo agente patológico da família do coronavírus causador da síndrome respiratória aguda (primeiramente denominada de SARS-CoV-2), que acometeu abruptamente inúmeros pacientes na cidade de Wuhan (Hubei, China). Em 30 de janeiro de 2020, a comunidade científica junto à Organização Mundial de Saúde reconheceu a propagação mundial da doença 2019nCoV (COVID-19) como uma emergência internacional de saúde pública e seu potencial pandêmico.

Os pacientes apresentam sintomatologias semelhantes a patologias gripais com evolução dos sintomas de maneira rápida, podendo ocasionar em insuficiência respiratória, sistêmica e pneumonia severa. Os sintomas mais comuns são febre, tosse seca e cansaço, e em alguns casos, dor de garganta, dificuldade respiratória, falta de ar, dor nas costas, batimento de asas nasais, padrão respiratório ineficaz, redução da saturação de oxigênio periférico, perda do olfato e perda do paladar, náuseas, coriza e diarreia (OPAS, 2020).

A difusão abrupta de numerosos casos em todos os continentes colocou em risco todos os fluxos de atendimento nos sistemas de saúde. Nações como Itália, Estados Unidos, Brasil, Espanha, Portugal e dentre outras encontraram-se à beira do colapso na assistência de saúde, necessitando da mobilização de órgãos de saúde pública como a Organização Mundial de Saúde (OMS) e a Organização Panamericana de

RC: 88690

Disponível em: https://www.nucleodoconhecimento.com.br/saude/meditacao-em-situacao 
Saúde (OPAS) para propor uma série de medidas no manejo da COVID-19, a fim de conter o avanço desenfreado da doença. (CHEN, 2020).

Todos os esforços primeiramente basearam-se em um complexo plano de contingência para evitar maior disseminação da doença e redução da velocidade na curva de propagação do vírus na população, a fim de que às instituições hospitalares pudessem capacitar-se para assistir dignamente os pacientes acometidos e evitar o colapso total do sistema de saúde.

Desde o início da pandemia, a OMS busca adquirir um conhecimento juntamente com autoridades chinesas e especialistas globais, objetivando aprender mais sobre o SARS-CoV-2 e como ele afeta as pessoas que estão doentes pelo mesmo (OPAS, 2020). Atualmente, os dados de casos confirmados no Brasil são atualizados diariamente pelo Ministério da Saúde (MS), além disso, a John Hopkins University vem monitorando ativamente os casos de COVID-19 ao redor do mundo.

\subsection{O DISTANCIAMENTO SOCIAL E SUAS REPERCURSSÕES PSICOEMOCIONAIS}

A transmissão do COVID-19 acontece principalmente através do contato de gotículas respiratórias. Um indivíduo que possui o SARS-CoV-2 já incubado pode transmitir o vírus ao tossir, espirrar ou falar. Embora a propagação dessas gotículas seja rápida, não viajam tão longe por serem pesadas, entretanto, podem permanecer em uma superfície por até 72 horas, ressaltando a importância do distanciamento social (OPAS, 2020).

Houve uma grande preocupação diante da rápida disseminação de COVID-19 em várias regiões do mundo, com diferentes impactos. Medidas de distanciamento social parcial e/ou por completo (lockdown) foram aplicadas como o instrumento primordial para minimizar a transmissão do vírus, definida através da restrição de atividades nãoessenciais, de acordo com os termos da Lei federal oㅜ 13.979, de 6 de fevereiro de 2020 (BRASIL, 2020).

RC: 88690

Disponível em: https://www.nucleodoconhecimento.com.br/saude/meditacao-em-situacao 
Com o objetivo de reduzir o risco de transmissão da doença, o isolamento social ocasiona a separação de indivíduos doentes das pessoas não infectadas, como forma de minimizar a propagação do contágio (WILDER, 2020). Contudo, essas ações só são eficazes quando realizada a detecção precoce do agente etiológico. Cada agente possui um tempo de incubação, e de acordo com estudos, o período de incubação dos coronavírus humanos é de 3 a 5 dias (NISHIURA, 2012).

Um longo período de incubação ocasiona um maior intervalo para identificação dos casos e colocá-los em isolamento. Além disso, há evidências de que indivíduos assintomáticos com SARS-CoV-2 apresentam cargas virais semelhantes aos pacientes sintomáticos, demonstrando a necessidade do aperfeiçoamento dos métodos de identificação do portador de COVID-19, para que o isolamento social seja efetivo (ZOU, 2020).

Outra opção para impedir a disseminação do vírus são medidas de distanciamento social, sendo aplicadas para aumentar a distância física entre pessoas potencialmente infectadas, mas que ainda não apresentaram sintomas (WILDER, 2020). Esse distanciamento consiste no fechamento de locais como escolas, que podem promover suas atividades de maneira online; a suspensão de comércios; desenvolvimento de teletrabalho nas empresas e reuniões remotas. Entretanto, essas medidas de distanciamento social possuem alguns desafios como o sentimento de isolamento da família e amigos, perda de liberdade e consequências financeiras devido à impossibilidade produtiva no local de trabalho (QUALLS, 2017).

Esses desafios enfrentados durante a pandemia tornam os indivíduos saudáveis mais susceptíveis ao desencadeamento de oscilações psicoemocionais como medo, ansiedade e depressão. Além disso, pode ocorrer a intensificação desses desequilíbrios nas pessoas em condições de saúde mental previamente abalada e pré-existente (QIU, 2020).

Nesse contexto, ao mesmo tempo que se acompanha avanços nos campos tecnológicos, é constatado um empobrecimento nas relações interpessoais. Antes RC: 88690

Disponível em: https://www.nucleodoconhecimento.com.br/saude/meditacao-em-situacao 
mesmo dos indícios de uma pandemia dessa magnitude, tal como o distanciamento social e suas repercussões psicoemocionais, já era possível observar evidências de uma sociedade à beira de um colapso ansioso, demonstrado por crescentes ocorrências de eventos violentos nas escolas, aumento do número de suicídio, bullying e o excessivo uso de medicamentos ansiolíticos em idades cada vez mais precoce.

As crianças também estão sujeitas aos fatores desencadeadores de oscilações emocionais e desajustes psicológicos. Tal fato pode ser exemplificado na exacerbação de novos meios de comunicação sem o contato físico e a cobrança precoce de valores baseados no "ter" em detrimento da valorização do "ser". Nesse cenário, nota-se que as crianças vivenciam uma realidade cada vez mais solitária com apelos individualistas, discriminações e isolamentos psicofísicos e emocionais ao substituir a vida real por contatos virtuais (BOFF, 2007).

O distanciamento das relações físicas dificulta o aprendizado da autogestão emocional, bem como corrobora na expansão de múltiplos conflitos entre grupos, levando inclusive a uma nova convivência no ritmo familiar. Além disso, o elevado número de doenças psicossomáticas transparece no aumento de eventos de desajustes na sociedade.

O autoconhecimento e a expansão da consciência levam o ser humano a se perguntar quem ele é; qual é o seu papel e a sua importância; qual é a sua atuação; as suas responsabilidades consigo e com o ecossistema no qual ele encontra-se inserido, favorecendo oportunidades de compreensão das próprias necessidades de cuidado, como elas afetam a si mesmo e refletem no todo, acolhendo uma visão holística das interações humanas e consequentemente amplificando os sentimentos empáticos entre todos.

Essa reflexão das necessidades básicas do cuidado humano proporciona o autoconhecimento e, ao aprender a cuidar de si, o indivíduo avalia como as suas

RC: 88690

Disponível em: https://www.nucleodoconhecimento.com.br/saude/meditacao-em-situacao 
próprias ações de cuidado refletem no meio e nas interações com os outros, podendo ser definido como empatia dentro da visão do cuidado holístico.

\subsection{A EMPATIA COMO UMA MANIFESTAÇÃO DO AUTOCONHECIMENTO, AUTOCUIDADO E CUIDADO COM O OUTRO}

Neurocientistas, psicólogos e filósofos contemporâneos referem que a empatia é composta por um "agente" e um "alvo", sendo uma relação de emoções entre pessoas. A empatia se inicia quando um estímulo emocional é ativado através de gestos, expressões faciais, comunicação ou vocalização. Essa ativação sem a percepção do agente acontece de forma automática, fazendo com que o estado emocional do agente se torne mais parecida com o do alvo. Logo, empatia é um mecanismo inato, entretanto, há indícios de que a empatia pode ser aprendida (HEYES, 2018).

A pandemia trouxe à tona diversos impactos, envolvendo efeitos negativos e positivos. Desde o início da COVID-19 a OMS vem atualizando um guia de informações com recomendações sobre o uso de máscaras, onde é exigido a utilização por todos, independentemente de ser assintomático ou não, como uma forma de conter a propagação do vírus.

O uso das máscaras é uma estratégia para se proteger e proteger o próximo do contato de gotículas salivares contaminadas, logo, pode ser vista como uma demonstração de empatia entre pessoas (OPAS, 2020). No entanto no início destas recomendações houve um aumento na procura de compra por máscaras cirúrgicas, gerando uma escassez deste produto. Tal conduta alarmou todos os órgãos competentes de saúde e a OMS enfatizou a importância de priorizar o uso das máscaras cirúrgicas e respiradores, como a N95, para profissionais da saúde.

Sendo tais produtos essenciais na assistência médica hospitalar, buscou-se medidas que despertassem empatia da população, a fim de restringir a compra destes insumos pela população em geral e priorizar o seu uso aos profissionais de saúde. Como exemplo, sugeriu-se a confecção de máscaras caseiras de tecido em substituição das RC: 88690

Disponível em: https://www.nucleodoconhecimento.com.br/saude/meditacao-em-situacao 
máscaras descartáveis, que continuam cumprindo a finalidade de ofertar prevenção ao indivíduo comum. Este cenário reflete as estratégias que podem beneficiar o maior número de pessoas e ao mesmo tempo evitar a escassez de recursos essenciais, priorizando ações focadas de acordo com a necessidade real de cada situação.

Embora a uso das máscaras seja de fundamental importância e possa ser considerado uma medida de empatia, ele gera perdas na expressão de comunicação não-verbal. As nossas expressões faciais são ferramentas importantes utilizadas para denotar sentimentos como: raiva, medo, tristeza e surpresa, dentre outros. A minimização nas expressões prejudica a construção do relacionamento humano, como por exemplo, a exteriorização dos sentimentos do profissional da saúde para com o paciente (HAFI, 2020).

Em outras palavras, uma sociedade na qual vivencia essa nova realidade imbuída de distanciamento das relações humanas, ausência de interações sociais, precárias ações que estimulem o autoconhecimento e a incapacidade de autogestão emocional, podem resultar em manifestações massivas dos efeitos da ansiedade.

\subsection{A CRESCENTE ANSIEDADE DURANTE À PANDEMIA SARS-COV-} 19

Antes mesmo das determinações de distanciamento e/ou isolamento social por completo, a simples difusão da notícia de uma rápida disseminação viral na qual se tem incertezas, perda da liberdade, mudança de rotinas, ausência de suprimentos habituais, disseminação de informações falsas através de redes sociais e o tédio são fatores que em uma pandemia podem intensificar os sintomas de depressão, ansiedade e estresse (SCHMIDT, 2020). Esses mecanismos de defesa que são gerados pelo organismo e manifestados em situações de perigo englobam aspectos comportamentais, fisiológicos e cognitivos, além de submeter o organismo a modificar sua homeostasia e acionar mecanismos de adaptação. (MARGIS, 2003).

RC: 88690

Disponível em: https://www.nucleodoconhecimento.com.br/saude/meditacao-em-situacao 
Ainda no início da pandemia, um estudo realizado na China com 52.730 indivíduos obteve como resultado $35 \%$ dos entrevistados que apresentavam algum sofrimento psicológico (QIU, 2020). Além disso, outro estudo turco que analisou os níveis de ansiedade e depressão em 343 pessoas durante a pandemia do COVID-19 resultou em $23,6 \%$ e 45,1\% de acometimento psicológico, respectivamente. (OZDIN, 2020).

Dessa forma, a ansiedade pode se apresentar como um estado de medo ou temor injustificado, sintomas de nervosismo motivado por circunstâncias reais ou imaginárias, desencadeando uma elevação dos batimentos cardíacos, transpiração excessiva e muitos outros sintomas como dor de estômago, tonturas e enxaqueca (NANTHAKUMAR, 2017). O sentimento de insegurança proveniente nesta nova maneira de vivermos isolados em uma pandemia e toda a sua complexa mudança na rotina é algo capaz de afetar, inclusive, pessoas saudáveis ao provocar instabilidade na saúde mental e intensificar tais sintomas em indivíduos que já apresentavam sinais de ansiedade e depressão.

Observando o contexto psicoemocional gerado por meio desse novo modo de viver em distanciamento e restrição das interações pessoais, busca-se através desta pesquisa verificar instrumentos que possibilitem melhor gestão da ansiedade, considerando uma técnica que possa ser incorporada por todos independentemente dos mínimos recursos econômicos para ser implementada. Portanto, considerando o contexto complexo ocorrido mundialmente durante a situação de distanciamento social e seus efeitos psicoemocionais, objetivou-se neste estudo as relações dos efeitos da meditação em situações de ansiedade e no desencadear de sentimentos de empatia.

\section{MATERIAL E MÉTODO}

Para a realização do presente trabalho, foi realizada um estudo analítico e descritivo a partir de uma revisão de literatura. A revisão de literatura possibilita o norteamento de uma problemática atual. Considera-se os critérios de ineditismo de um estudo e a

RC: 88690

Disponível em: https://www.nucleodoconhecimento.com.br/saude/meditacao-em-situacao 
validação do objeto de pesquisa como instrumentos fundamentais a fim de propiciar a indicação de sentidos inovadores e a expansão de investigações empíricas (MOREIRA, 2016).

Em relação aos resumos, foram consultadas as bases de dados Scientific Eletronic Library Online (SciELO); Biblioteca Virtual em Saúde (BVS); National Library of Medicine and National Institutes of Health (PubMed); ResearchGate e Instituto Brasileiro de Informação em Ciência e Tecnologia (IBICT), utilizando-se dos seguintes Descritores em Ciências da Saúde (DeCS): Empatia AND Meditação; Ansiedade AND Infecção por coronavírus e Saúde mental AND Meditação AND Empatia.

Para a seleção dos estudos foram utilizados os seguintes critérios de inclusão: Artigos publicados entre os períodos de 2003 a 2020, nos idiomas português e inglês, que contemplassem os descritores selecionados e que possuíssem dados relevantes em relação às contribuições da meditação em suscitar empatia e redução da ansiedade. Artigos que não apresentaram relevância para o estudo ou dados insuficientes e revisões foram englobados nos critérios de exclusão.

A busca inicial desta pesquisa apresentou um total de 946 produções (artigos, teses e dissertações) relacionadas à meditação e educação holística. Destas foram selecionadas 01 tese, 04 dissertações e 20 artigos para serem estudados na íntegra por apresentarem relação direta com efeitos da meditação em eventos de ansiedade, o despertar dos sentimentos de empatia por intermédio de tal prática e as oscilações psicoemocionais desencadeadas durante a pandemia.

\section{DISCUSSÃO E REVISÃO DE LITERATURA}

\subsection{AS PRÁTICAS MEDITATIVAS E SUAS RAÍZES}

De acordo com o Ministério da Saúde, a meditação pode ser definida como uma prática de saúde integrativa para o cuidado e, através de sua aplicabilidade, estimulase o foco da atenção de modo não analítico ou discriminativo, sendo capaz de RC: 88690

Disponível em: https://www.nucleodoconhecimento.com.br/saude/meditacao-em-situacao 
promover alterações favoráveis no humor e no desempenho cognitivo (BRASIL, 2015).

A meditação é um estado de consciência atingível por todos, apresentando-se como uma filosofia prática de vida. Achados históricos apontam a civilização índica como a mais antiga civilização contínua do mundo, relacionando artefatos arqueológicos com a data de sete milênios a.C. As primeiras definições, conceitos e preceitos de meditação encontram-se dentro de um grande sistema filosófico da Índia antiga, denominado yoga. O yoga possui várias escolas filosóficas com diferentes abordagens, logo, tais ensinamentos se correlacionam de forma interligada aos inúmeros conceitos sobre a visão de homem, mundo, saúde e corpo, estudando por milênios as interações entre a mente e a respiração, tornando essa interligação como uma das mais fundamentais para o domínio da energia vital (FEUERSTEIN, 2005).

Quando um indivíduo se encontra ansioso ou com as emoções alteradas, a respiração fica mais ofegante, a frequência cardíaca se altera, a pressão arterial se modifica, perturbando vários outros sinais vitais. As oscilações mentais e emocionais desenfreadas utilizam demasiadamente uma energia que poderia ser poupada ou potencializada para ser empregada de maneira mais proveitosa, além de converter mais energia para a concentração, o foco, a melhoria no metabolismo do corpo físico, as conexões mentais e a digestão de emoções.

Nesse sentido, durante as pesquisas incluídas no levantamento dos dados, foram verificados alguns benefícios emocionais mais frequentes após a inclusão da meditação e/ou yoga. Entre eles, a potencialização das sensações de calma e relaxamento, que serão a seguir comentados.

\subsection{CONTRIBUIÇÕES DA MEDITAÇÃO NOS EFEITOS DE ANSIEDADE E PROMOÇÃO DA EMPATIA}

A ansiedade muitas vezes se manifesta frente a situações de medo e ao enfrentamento de estímulos reais ou mentais. A internalização promovida pela RC: 88690

Disponível em: https://www.nucleodoconhecimento.com.br/saude/meditacao-em-situacao 
meditação propicia o autoconhecimento e o autoestudo para analisar situações que desencadeiam oscilações emocionais. Além disso, a técnica melhora a modulação em regiões específicas do cérebro, responsáveis pelos controles de alerta e euforia.

Através do autoconhecimento, é transcorrido a internalização dos problemas, melhora na capacidade de identificar falhas e exploração dos pontos positivos frente às dificuldades ao promover menores índices de ansiedade, visto que as situações desafiadoras foram revistas mentalmente com menores estímulos emocionais. Ademais, essas ferramentas possibilitam o melhor desempenho cognitivo, com o foco no aqui e agora, e menores reações de fuga dos eventos estressantes.

A modulação fisiológica desencadeada pelas técnicas respiratórias e meditativas podem ser mensuradas através da estabilização dos parâmetros de pressão arterial, melhora na variabilidade da frequência cardíaca e até mesmo com exames de eletroencefalograma que apontam regiões cerebrais influenciadas pelo estímulo. Os sentimentos de autocontrole e resiliência, muitas vezes, são reflexos dos efeitos provocados por tais intervenções, apresentando-se como uma ferramenta de promoção para o autoconhecimento e dentro de uma gama de estratégias, pode auxiliar na transformação de uma comunidade mais humana e empática. (DENARDO, 2017).

A interiorização, por meio de técnicas meditativas que se utilizam de visualização exercícios respiratórios e repetição sistemática de frases ou orações -, desencadeiam melhoras nas oscilações emocionais. Dessa forma, uma experiência educativa realizada em uma escola pública de Fortaleza (CE) proporcionou um semestre de práticas de meditação com 120 alunos, resultando em 66\% de progresso emocional nos participantes como melhora no bem-estar pessoal, concentração em sala de aula, relacionamento familiar e no espaço educativo, além de melhor desempenho escolar. (SAMPAIO, 2012).

O convívio de crianças da educação infantil no ambiente escolar através dos fundamentos da pedagogia da autonomia, oportuniza o desenvolvimento da RC: 88690 
independência e cooperação nas relações ao evidenciar a meditação como uma parte lúdica para rever os aprendizados diários e ampliar os sentimentos de resiliência. Desta forma, torna-se notável o benefício aos alunos com menores níveis de ansiedade (ANTUNES, 2018).

Em outro estudo no qual se incluiu sessões meditativas promovidas com homens adultos saudáveis e sem oscilações emocionais agudas, utilizando-se da técnica de respiração abdominal lenta, foi apontado melhoras na variabilidade e função autonômica cardíaca. Além disso, exames específicos também indicaram o estímulo em regiões cerebrais responsáveis na modulação de estresse, euforia, ansiedade, alerta e dor. (MACHADO, 2015).

A melhora na variabilidade da frequência cardíaca e a modulação autonômica do sistema nervoso, através da técnica de respiração, também foi evidenciada em um amplo estudo realizado na Índia, com 145 homens adultos portadores de doença cardíaca isquêmica com e sem diabetes. $E$, durante 1 ano após a intervenção, os pacientes obtiveram uma redução na sintomatologia funcional, encorajando a prática como uma terapia não-farmacológica, segura e psicologicamente aceitável. (KULLUR et al, 2009).

A autocompaixão e a empatia relacionam-se com capacidade de compreender amorosamente a dor e o sofrimento do outro, assimilando que estes sentimentos podem afetar a si mesmo. A meditação mindfulness foi efetiva enquanto instrumento promotor de melhor aceitação das dificuldades e experiências desafiadoras na faixa etária dos adolescentes em um estudo realizado na Carolina do Norte (EUA), com crianças entre 12 e 17 anos que possuíam sentimentos de autocompaixão, apresentaram menor incidência de estresse, ansiedade e maiores índices de satisfação pela vida. O pertencimento a um grupo e a compreensão de suas dificuldades refletem na autoanálise, autoaceitação e consequente relações mais empáticas e harmônicas (BLUTH, 2015).

RC: 88690

Disponível em: https://www.nucleodoconhecimento.com.br/saude/meditacao-em-situacao 
$\mathrm{Na}$ Califórnia, outro estudo com crianças do ensino infantil à fundamental demonstrou que após 12 semanas de meditação, inserido no contexto escolar, o respeito e o carinho com os outros estavam mais presentes. As crianças elevaram os níveis de autocontrole, participação nas atividades, calma, atenção e o processo de ensino e aprendizagem foi facilitado. Os professores sentiram menor sobrecarga do estresse e menor interrupção das inconveniências comportamentais. Os efeitos benéficos podem ser refletidos ao longo dos anos profissionais do docente, pois a sobrecarga estressante é fator que contribui para a evasão da carreira. Salas de aula menos conturbadas afetam a satisfação pela vida profissional dos professores. Portanto, as contribuições dos efeitos promovidos pela meditação englobam a conscientização empatia nos desafios e dificuldades de si e do outro e podem ser sentidas coletivamente (BLACK, 2014).

A interiorização de pequenos momentos silenciosos durante 0 dia permite 0 autoestudo, a conscientização e uma minuciosa avaliação de todas as ações que ocorrem durante o momento presente. Mesmo em pequenas intervenções, encontrase o relato do aumento da capacidade de autopercepção. A autopercepção promove a capacidade de identificar falhas, avaliar maneira de corrigi-las e evidenciar pontos positivos. (SOUZA, 2014).

Estudos apresentados com a inclusão da prática do yoga para crianças em idade escolar demonstrou declínio na estimulação sistema nervoso simpático, ocorrendo a regulação do eixo hipotálamo-pituitária-adrenal, e como consequência, afetando a liberação do cortisol. A taxa deste hormônio se altera em situações de maior estresse, logo, as crianças praticantes de yoga apresentaram relaxamento dos nervos, desenvolvimento do estado de atenção plena e melhora na habilidade em lidar com situações de ansiedade e estresse (NANTHAKUMAR, 2017).

Nesse contexto, outro estudo experimental com crianças do ensino fundamental, na Coréia do Sul, demonstrou a mesma redução dos níveis de cortisol salivar após a

$\mathrm{RC}: 88690$

Disponível em: https://www.nucleodoconhecimento.com.br/saude/meditacao-em-situacao 
realização de 8 semanas de meditação, tendo como desfecho a atenuação das taxas de agressividade e ansiedade. (YOO et al, 2015).

Através da inclusão prática da meditação mindfulness, crianças canadenses que apresentavam desequilíbrios de ansiedade e depressão no ensino fundamental I, entre 9 e 10 anos, vivenciaram um experimento com 8 semanas de meditação. Através da introspecção foi possível identificar as situações que desencadeavam a ansiedade, permitindo a observação das próprias emoções e tomando consciência de quando elas não estão saudáveis. A conscientização das oscilações emocionais e de onde elas provêm, auxiliou na diminuição da ansiedade dessa população (MALBOEUFHURTUBISE et al, 2017).

Uma pesquisa de relevância bastante similar, com crianças italianas entre 7 e 8 anos em uma escola pública também apresentou benefícios. Após 8 semanas de meditação, foi evidente a redução na internalização e na reação impulsiva frente aos problemas e dificuldades. (CRESCENTINI et al, 2016).

$\mathrm{Na}$ Flórida, indivíduos avaliados com altas habilidades participaram do programa meditativo por 10 semanas, onde foi possível observar o relato de maior foco, menos ansiedade (embora alguns relataram a dificuldade de relaxamento progressivo dos músculos), mais tranquilidade e refinamento dos sentidos, incluindo o bloqueio voluntário de ruídos e distrações. (HABERLIN et al, 2017).

\section{CONSIDERAÇÕES FINAIS}

As práticas integrativas como a meditação e o yoga impulsionam a conscientização com responsabilidade das ações práticas consigo mesmo e com o meio no qual encontra-se inserido. Em outras palavras, reforça uma abordagem de compromisso e respeito sociocultural baseada na autonomia responsável de uma aprendizagem contínua em ser gente e reconhecer-se humano, que irá refletir em todas as esferas.

RC: 88690

Disponível em: https://www.nucleodoconhecimento.com.br/saude/meditacao-em-situacao 
A meditação, assim como muitos processos dentro da aprendizagem humana, não pode ser vista como algo isolado. Embora tenha-se encontrado evidências benéficas com a inclusão dessa prática, se pode perceber a multiplicidade de outras técnicas concomitantes, como o respirar adequado, a importância do desenvolvimento físico para se manter sentado corretamente, o feedback com as rodas de conversa, a escuta acolhedora, dentre outros. Enfatizando a consciência de que todos são igualmente providos de capacidades e dificuldades.

A ansiedade, como um evento desencadeado por sentimento de insegurança com futuro, falta de conectividade com o momento presente e medo pode ser minimizada por meio da prática da meditação, que demonstra efetividade em diversos estudos supracitados, incluindo crianças, jovens e adultos. Diante de um cenário em distanciamento social no qual o contato humano foi abruptamente privado em todos os hemisférios do planeta, os indivíduos foram instigados a refletirem nas consequências de seus próprios atos e como estes afetam a coletividade.

Conceitos universalistas e holísticos, os quais são enfatizados à milênios como um preceito básico do meditante. Compreende-se que, por meio da prática da meditação o meditante entra em contato com seus próprios medos, anseios e inseguranças. Aprende a se autoanalisar e muitas vezes identifica as mesmas dificuldades nos outros. Este processo de autoconhecimento leva à sentimentos de autocompaixão, compaixão e empatia. Por meio da empatia, os eventos de agressividade, falta de cuidado, violência e bullying com o próximo também é reduzido, pois amplia-se a consciência de que as ações, atitudes e sentimentos de um único indivíduo é capaz de afetar a todos.

A meditação não é apenas uma técnica solta, mas parte de uma filosofia de vida intrinsecamente conectada com pilares educativos, nutridos por princípios éticos e morais. Tais valores humanos encontram-se livres do sectarismo cultural, social, religioso ou econômico de uma sociedade, pois reforçam atitudes de cuidado consigo mesmo impactando em um todo.

$\mathrm{RC}: 88690$

Disponível em: https://www.nucleodoconhecimento.com.br/saude/meditacao-em-situacao 
Tais atitudes providas de sentimentos empáticos com o outro e consigo mesmo, elevam a patamares mais conscientes de uma responsabilidade global, em múltiplos aspectos no cuidado e no processo de ensino e aprendizagem humano.

Para aprender, ensinar e cuidar é necessária uma mudança de paradigmas individualistas para uma ótica ampliada nas ações e atitudes pessoais ressoando como ondas impactantes na evolução do indivíduo. Seres humanos que praticam o autoconhecimento reconhecem as dificuldades e a dor do outro, desenvolvem maiores sentimentos de empatia, compreensão e empoderamento nas ações individuais e coletivas. Promovem a consciência responsável de deveres e direitos igualitários ao reforçar o despertar de uma Nova Era com mais paz e respeito à todas as diferenças. É se tornar efetivamente humanizado e, por consequência, mais "gente".

Espera-se que esta singela contribuição possa semear e somar saberes rumo a uma cultura de paz nas escolas, nos lares, nas sociedades e nos corações de todos os seres. Pois acredita-se que por meio do desenvolvimento individual é possível alçar degraus mais elevados no crescimento coletivo.

\section{REFERÊNCIAS}

ANTUNES, D.S.H.Y. Da inovação em educação as escolas emergentes: papel social, valores e estratégias para a formação humana. 2018. 167f. Dissertação de Mestrado (Programa de Pós-Graduação em Educação) - Pontifícia Universidade Católica do Rio Grande do Sul, Porto Alegre, 2018.

BLACK D.S.; RANDIMA. F. Mindfulness training and classroom behavior among Lower-income and ethnic minority Elementary School Children. J Child Fam Stud, New York, v. 23, n. 7, p. 1242-1246, oct. 2014.

BLUTH K.; ROBERSON P.N.E.; GAYLORD S.A. A pilot study of a mindfulness intervention for adolescents and the potencial role of self-compassion in reducing stress. Explore (NY), New York, v. 11, n. 4, p. 292-295, jul/aug. 2015.

RC: 88690

Disponível em: https://www.nucleodoconhecimento.com.br/saude/meditacao-em-situacao 
BOFF, L. Saber cuidar: ética do humano - compaixão pela terra. 13. ed. Petrópolis: Editora Vozes, 2014. 302p.

BRASIL. Lei 13.979, de 6 de fevereiro de 2020. Dispõe sobre medidas para 0 enfrentamento da emergência de saúde pública de importância internacional decorrente do coronavírus responsável pelo surto de 2019. Diário Oficial da União Seção 1 - 7/2/2020, p.1.

BRASIL. Ministério da Saúde. Departamento de Atenção Básica. Política Nacional de Práticas Integrativas e Complementares no SUS: atitude de ampliação de acesso. 2. ed. Brasília: Ministério da Saúde, 2015. 96p.

CHEN, S. et al. Fangcang shelter hospitals: a novel concept for responding to public health emergencies. The Lancet, United Kingdom, v. 395, p. 1305-1314, apr. 2020.

CRESCENTINI C. et al. Mindfulness-Oriented meditation for Primary School Children: effects on attention and psychological well-being. Front Psychol, Pully, v. 7, p. 805, jun. 2016.

DENARDO, T. A. G. B. O "caminho do meio" na educação: discursos que formam pontes entre a meditação, ciência e educação. 2017. 39f. Dissertação de Mestrado (Programa de Pós-Graduação em Educação) - Universidade Estadual Paulista Júlio de Mesquita Filho, Rio Claro, 2017.

FEUERSTEIN, G. Uma visão profunda do yoga: teoria e prática. 1. ed. São Paulo: Editora Pensamento, 2005. 287p.

HAFI, B. et al. "Masked" empathy - A post-pandemic reality: psychodermatological perspective. Dermatol Ther, Copenhagen, e13649, may. 2020.

HABERLIN, S.; O'GRADY, P. Gifted from the "inside out": teaching mindfulness to high-ability children. Sage Journal, California, v. 34, n. 2, p. 173-180, may. 2018.

RC: 88690

Disponível em: https://www.nucleodoconhecimento.com.br/saude/meditacao-em-situacao 
HEYES, C. Empathy is not in our genes. Neurosci Biobehav Rev, Fayetteville, v. 95, p. 499-507, dec. 2018.

KULLUR, A. B. et al. Efeito da respiração diafragmática sobre a variabilidade da frequência cardíaca na doença cardíaca isquêmica com diabete. Arq Bras Cardiol, Rio de Janeiro, v.92, n. 6, p. 457-463, 2009.

MACHADO, D.G.S. Efeito agudo da respiração abdominal lenta sobre a atividade cerebral, respostas emocionais e cardiovasculares. 2015. 74f. Dissertação de mestrado (Programa de Pós-Graduação em Educação Física) - Universidade Federal do Rio Grande do Norte, Natal, 2015.

MALBOEUF-HURTUBISE C. et al. Mindfulness-based intervention in Elementary School Students with anxiety and depression: a serie of $n$-of-1 trials on effects and feasibility. J Evid Based Complementary Altern Med, California, v.22, n.4, p.856869, aug. 2017.

MARGIS, R. et al. Relação entre estressores, estresse e ansiedade. Rev Psiquiatr, Rio Grande do Sul, v. 25, n. 1, p. 65-74. abr. 2003.

NANTHAKUMAR, C. The benefits of yoga in children. J Integr Med, Shangai, v. 16, n.1, p. 14-19, dec. 2017.

NISHIURA, H. et al. Incubation period as part of the case definition of severe respiratory illness caused by a novel coronavirus. Euro Surveill, Saint-Maurice, v. 17, n. 42, p. 1-6, oct. 2012.

OPAS - Organização Pan-americana de Saúde. Folha informativa sobre COVID-19 [retirado da internet]. Brasília: Escritório regional para as Américas da Organização Mundial de Saúde, 2020. Disponível em: https://www.paho.org/pt/covid19. Acesso em: 03 fev. 2021.

RC: 88690

Disponível em: https://www.nucleodoconhecimento.com.br/saude/meditacao-em-situacao 
OZDIN, S.; OZDIN, S.B. Levels and predictors of anxiety, depression and health anxiety during COVID-19 pandemic in Turkish society: The importance of gender. Int J Soc Psychiatry, London, v. 66, n. 5, p. 504-511, aug. 2020.

QIU, J. et al. A nationwide survey of psychological distress among Chinese people in the COVID-19 epidemic: implications and policy recommendations. Gen Psychiatr, London, v. 33, n. 2, e100213, mar. 2020.

QUALLS, N.; et al. Community Mitigation Guidelines to Prevent Pandemic Influenza — United States, 2017. MMWR Recomm Rep, Atlanta, v. 66, n. 1, p. 1-33, apr. 2017.

SAMPAIO, D. D. F. Cultura de paz, educação e meditação com jovens em escola pública estadual de Fortaleza-Ceará. 2012. 163f. Tese em Doutorado (Doutorado em Educação Brasileira) - Universidade Federal do Ceará, Fortaleza, 2012.

SCHMIDT, B. et al. Saúde mental e intervenções psicológicas diante da pandemia do novo coronavírus (COVID-19). Estud Psicol, Campinas, v. 37, e200063, mai. 2020.

SONIS, J. et al. Humanism in the Age of COVID-19: Renewing Focus on Communication and Compassion. West J Emerg Med, California, v. 21, n. 3, p. 499502, apr. 2020.

SOUZA, A. M. Práticas autoformativas na formação continuada do educador na perspectiva de um sujeito ecológico. 2014. 128f. Dissertação em Mestrado (Mestrado em Educação) - Universidade de Brasília, Brasília, 2014.

WILDER, S. A.; FREEDMAN, D. Isolation, quarantine, social distancing and community containment: pivotal role for old-style public health measures in the novel coronavirus (2019-nCoV) outbreak. J Travel Med, Ontario, v. 27, n. 2, p. 1-4, mar. 2020.

RC: 88690

Disponível em: https://www.nucleodoconhecimento.com.br/saude/meditacao-em-situacao 
YOO Y.G. et al. The effects of Mind Subtraction on depression, social anxiety, aggression and salivary cortisol levels of Elementary School Children in South Korea. J Pediatr Nurs, Orlando, v.31. n. 3. p. 185-197. may/jun. 2016.

ZOU, L. et al. SARS-CoV-2 Viral Load in Upper Respiratory Specimens of Infected Patients. N Engl J Med, Massachusetts, v. 382, n. 12, p. 1177-1179, mar. 2020.

Enviado: Abril, 2021.

Aprovado: Junho, 2021. 